\title{
Long term clinical outcome of coronary surgery and assessment of the benefit obtained with postoperative aspirin and dipyridamole
}

\author{
A H GERSHLICK, J P LYONS, J E C WRIGHT, M F STURRIDGE, C A LAYTON, \\ R BALCON
}

From the Department of Cardiology, London Chest Hospital, London

SUMMARY Three hundred and twenty patients originally entered into a randomised study to assess the effect of aspirin and dipyridamole on the patency of coronary bypass grafts one year after operation were clinically reassessed a mean of 6.6 years (range 4.3-8.6) after operation. Patients were recruited between 1978 and 1982 after the present policy of total revascularisation had been adopted. During the follow up period there were 25 deaths of which 17 were due to cardiac causes (average annual cardiac mortality $0 \cdot 8 \%$ ). Of 280 patients available for contact, $250(89.3 \%$ ) attended an outpatient interview. Ninety four $(37.6 \%)$ patients complained of recurrent angina but in only $23(9.2 \%)$ was this severe. Two hundred and eleven $(84.4 \%)$ of the 250 patients underwent exercise stress testing. There were $73(34.6 \%)$ abnormal tests of which 52 were in the group of 94 patients with recurrent angina. Myocardial infarction occurred in nine of the 250 patients during the follow up period. Twenty six patients $(10.4 \%)$ had reinvestigation for symptoms. This group had a graft occlusion rate of $52 \%$. Half these patients have required reoperation and 20 of 22 occluded or severely stenosed grafts were replaced. In only two instances were vein grafts inserted into vessels with new disease. Half of the original group were given aspirin ( $330 \mathrm{mg}$ three times a day) plus dipyridamole ( $75 \mathrm{mg}$ three times a day). Of the 250 patients interviewed, 122 took aspirin and dipyridamole from the second postoperative day for a mean of 25 months, with warfarin for three months. The other 128 patients took placebo for a mean of 23 months together with warfarin for three months. This long term treatment with aspirin plus dipyridamole conferred no significant benefit for all clinical outcomes measured at a mean of 6.6 years.

Coronary artery surgery is routinely performed as a treatment for ischaemic heart disease. As well as relieving symptoms the operation has also been shown to improve survival in certain patients. ${ }^{1-3}$ These trials, undertaken in the 1970 s, have also helped to determine the change int graft patency rates with time. We report a further series of patients undergoing coronary artery bypass grafting after the introduction of a policy of total revascularisation.

We studied 320 patients who entered a trial between 1978 and 1982 at the London Chest Hospital. The trial was designed to assess the effect of aspirin and dipyridamole on vein graft patency at one

Requests for reprints to Dr A H Gershlick, Department of Cardiology, London Chest Hospital, Bonner Road, London E2 9JX.

Accepted for publication 24 March 1988 year. One hundred and sixty patients were randomised to receive aspirin (330 $\mathrm{mg}$ ) and dipyridamole $(75 \mathrm{mg})$ three times a day and 160 to placebo. Both groups took warfarin for the first three months after operation."

We reassessed the longer term outcome of this group of patients entered into a previously reported study of vein graft patency at one year, and we evaluated the effect of aspirin and dipyridamole on longer term clinical outcome.

\section{Patients and method}

Between 1978 and 1982, 320 consecutive patients were entered preoperatively into a randomised study to assess the effects on one year graft patency of aspirin and dipyridamole plus warfarin versus placebo plus warfarin. All 320 patients entered into 
the original study were considered for the clinical reevaluation undertaken in the present study. Mortality was measured first. All patients undergoing coronary angiography (and thus coronary surgery) at the London Chest Hospital are "flagged" to allow return of any subsequent death certificates to the London Chest Hospital. The number of deaths during follow up could thus be recorded accurately.

Apart from five patients, who asked not to be contacted, all surviving patients were asked to attend an outpatient clinic, during a six month period in 1986. The outpatient interview was performed by one person who was unaware of the patient's original randomisation category. Information was documented on a standard questionnaire. The presence or absence of angina was determined, together with its severity (graded according to the Canadian Cardiovascular Society (CCS) classification), its time of onset after operation, and the use of antianginal medication (aspirin and dipyridamole plus warfarin or placebo plus warfarin). Patients were also asked how long they had taken their trial medication. We asked for information on admission to hospital for myocardial infarction. The hospitals were subsequently contacted for confirmation of myocardial infarction, with only electrocardiographic criteria or enzyme change being accepted as evidence. Work status before and after surgery was recorded. All patients were asked about their smoking habits.

Information on repeat angiography and reoperation during the follow up period was documented and the inpatient notes of these patients were reviewed to ascertain angiographic findings and reoperation details.

All patients were asked to undertake an exercise stress test according to the modified Bruce protocol. The test was stopped and regarded as abnormal if angina or ST segment depression $>1 \mathrm{~mm}(80 \mathrm{~ms}$ beyond the J point) developed.

The preoperative left ventricular angiograms of all patients were visually analysed by classifying each of three wall segments (anterior, apical, and inferior) as normal or abnormal.

\section{Results}

MORTALITY

Thirty five of the original 320 patients died from the time of entry to time of reassessment (overall mortality $10.9 \%$ ). Three died while waiting for an operation and seven died perioperatively (perioperative mortality $2.2 \%$ ). Eight of the remaining 25 deaths were from non-cardiac causes. The 17 postoperative cardiac deaths occurred a mean of 37 months after operation and the average annual cardiac mortality was $0.8 \%$. Fifteen $(56 \%)$ of the 27

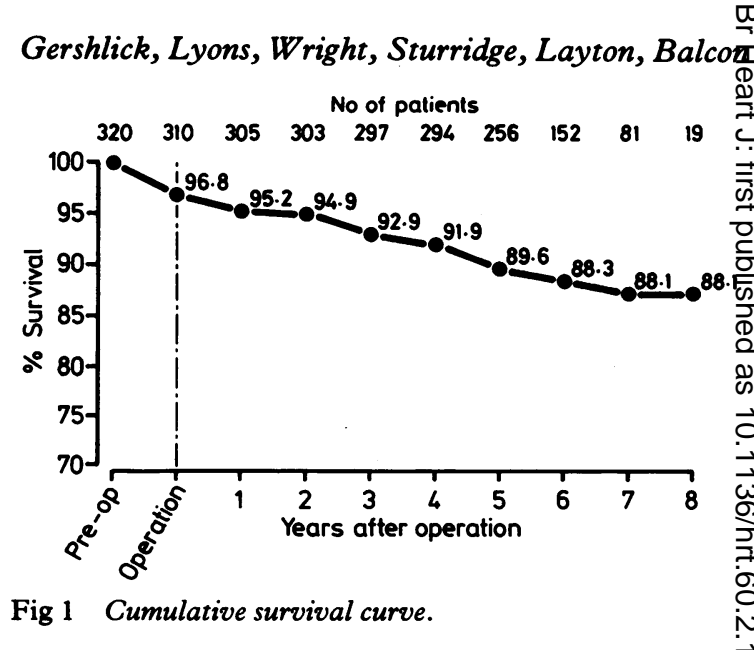

cardiac deaths (preoperative, perioperative, and postoperative) were in patients with two or more abnormal segments on the preoperative left ven tricular angiogram. Eighty nine $(30.4 \%)$ of the $28 \%$ survivors had abnormal left ventriculograms ( $p \&$ 0.01 ). Figure 1 shows the cumulative survival curve for all patients (deaths from cardiac plus non-cardiaco causes).

\section{Follow up patients}

Two hundred and fifty $(87.7 \%)$ of the 285 survivor attended the outpatient interview. Twenty eight of the 35 who did not reply had previously refuse $\$$ recatheterisation at one year. The mean time fron $\overrightarrow{5}$ operation to follow up interview was 6.6 years (range 4.3-8.6).

\section{SYMPTOMS}

\section{Angina}

Ninety four $(37.6 \%)$ patients complained of recurrent angina but in only $23(9 \cdot 2 \%)$ was this. severe (grade III or IV). Eighty five patients werg taking antianginal medication including $\beta$ blocking drugs in 52 . In eight patients angina persisted despite a further operation. Figure 2 shows the cumulative incidence of angina.

Nine patients had had a myocardial infarction. which was confirmed by electrocardiogram of enzyme change in all cases.

\section{Work status}

Of the 250 patients interviewed, $205(82.0 \%)$ were working before the operation. Twenty six (10.4\% reached retirement age during the follow up perio 8 and a further $35(14.0 \%)$ failed to return to worto either because they did not wish to or because the were retired on medical grounds. So 144 patients $(56.8 \%)$ were in full time or part time employment mean of 6.6 years after operation. 


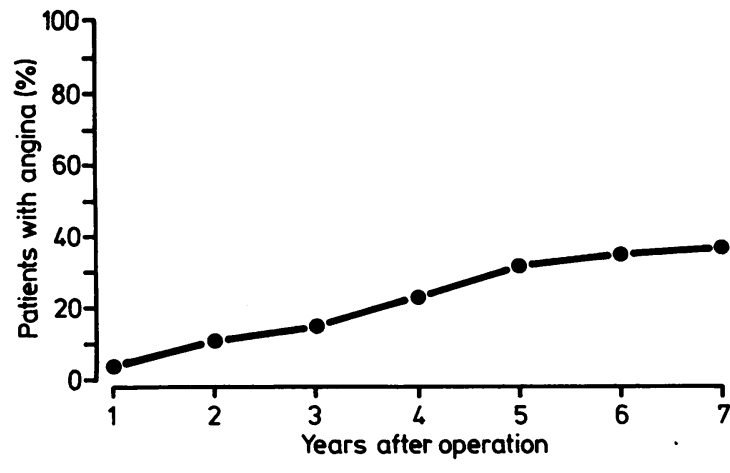

Fig 2 Cumulative incidence of angina.

\section{Smoking}

One hundred and fifty six (48.7\%) of the original 320 patients smoked cigarettes before operation. Sixty six $(26.4 \%)$ patients were smokers at the time of interview.

\section{Reinvestigation}

Twenty six $(10.4 \%)$ of the 250 patients underwent repeat angiography for symptoms at a mean of $\mathbf{4 8}$ months (range 4-96) after operation. In these 26 patients 72 vessels had been grafted at operation and $38(52 \cdot 7 \%)$ grafts were found to be occluded or significantly stenosed. This compares with a graft occlusion rate of $13 \%$ at one year for all patients entered and a one year occlusion rate of $29 \%$ for these 26.

\section{Reoperation}

Reoperation was performed in 13 patients (twice in one patient) at a mean of 33.4 months (range 4-96) after the first operation. There were 34 original grafts, and at reinvestigation $22(64.7 \%)$ grafts were occluded or severely stenosed. At reoperation 20 of these 22 originally grafted vessels were revascularised. In only two instances were grafts inserted into diseased vessels not originally grafted.

\section{Exercise stress testing}

Two hundred and eleven $(84.4 \%)$ of the 250 patients were willing or physically able to perform an exercise test. Table 1 shows the results of the exercise tests.

There were $73(34.6 \%)$ abnormal tests, 52 in the 94 patients with recurrent angina and 21 in the 117

Table 1 Exercise tests in 211 patients

\begin{tabular}{lrcc}
\hline & & Ischaemic & Non-ischaemic \\
\hline & & $73(34 \%)$ & 138 \\
Recurrent angina & 94 & $52(55 \%)$ & 42 \\
No recurrent angina & 117 & $21(18 \%)$ & 96 \\
\hline
\end{tabular}

Table 2 Clinical outcome in patients given aspirin and dipyridamole or placebo

\begin{tabular}{|c|c|c|c|c|}
\hline & No & $\begin{array}{l}\text { Aspirin } \\
\text { and } \\
\text { dipyridamole }\end{array}$ & Placebo & $p$ \\
\hline $\begin{array}{l}\text { Patients interviewed } \\
\text { Cardiac deaths } \\
\text { Angina } \\
\text { Myocardial infarction } \\
\text { Ischaemic exercise test } \\
\text { Repeat angiography } \\
\text { Further operation }\end{array}$ & $\begin{array}{r}250 \\
27 \\
94 \\
9 \\
73 \\
26 \\
13\end{array}$ & $\begin{array}{r}122 \\
13 \\
49 \\
7 \\
39 \\
12 \\
5\end{array}$ & $\begin{array}{r}128 \\
14 \\
45 \\
2 \\
34 \\
14 \\
8\end{array}$ & $\begin{array}{l}\text { NS } \\
\text { NS } \\
\text { NS } \\
\text { NS } \\
\text { NS } \\
\text { NS } \\
\text { NS }\end{array}$ \\
\hline
\end{tabular}

patients without recurrent symptoms ( $p<0.001)$. Six of the 13 patients who had undergone further surgery developed abnormal exercise tests.

\section{EFFECT OF ASPIRIN AND DIPYRIDAMOLE ON} LONG TERM CLINICAL OUTCOME

In the original study 160 patients were randomised to active treatment and 160 to placebo. One hundred and twenty two of the $\mathbf{2 5 0}$ patients interviewed at a mean of 6.6 years had been on active treatment for a mean of 25 months (range 0-63) and 128 had been on the placebo. All patients took warfarin for a mean of 3.2 months after the operation. Aspirin and dipyridamole conferred no significant clinical benefit at a mean of 6.6 years after operation (table 2). Ten patients died before receiving any medication; treatment was started on the second postoperative day. ${ }^{4}$ Of the 17 patients who died during the follow up period nine took aspirin and dipyridamole and eight took placebo (NS).

\section{Discussion}

Aortocoronary bypass grafting is an accepted form of treatment for patients with ischaemic heart disease. Much is known about the indications for, and natural history of, such grafts. The European study and the Coronary Artery Surgery Study indicated that surgery improves the outcome in certain groups. Follow up studies on graft patency suggest a failure rate of $10 \%$ in the first three months ${ }^{5-7}$ and an annual attrition rate of about $2.5 \%$ for the first five years and thereafter one of about $5 \%$ per annum. ${ }^{89}$

Patients entered into the Veterans Administration Study between 1972 and 1974 were re-evaluated 11 years after the start of the study. ${ }^{10}$ At re-evaluation the survival rate was $58 \%$ for both medical and surgical groups; at seven years it was $70 \%$ and $77 \%$ respectively. Other studies have shown that the graft patency rate falls with time. ${ }^{89}$ Thus graft survival data and long term follow up data suggest that the benefits of vein grafting decrease significantly between seven and 11 years. Patients were entered into 
these trials, however, before the development of a policy of total revascularisation in the late 1970s. There have been no long term British follow up studies in patients who have undergone total revascularisation. Additionally, since angioplasty is being increasingly used for the treatment of ischaemic heart disease, the longer term benefits of coronary surgery need to be restated.

The patients in the present study were recruited between 1978 and 1982 . The perioperative mortality $(2 \cdot 2 \%)$ compares well with that of other studies. The work of Bourassa et al and Seides et al, who showed that progression of native disease was an important cause of new symptoms after vein grafting, ${ }^{112}$ led to the concept of total revascularisation. The present study started when total revascularisation was the practice at the London Chest Hospital. This may account for the favourable clinical outcome demonstrated at follow up study. At 6.6 years after operation $87.1 \%$ of patients were alive compared with $\mathbf{8 7} \%$ for the Coronary Artery Surgery Study at six years and $77 \%$ for the Veterans Administration Study at seven years. In our follow up, as in other studies, left ventricular dysfunction was a bad prognostic factor.

Recurrent angina developed in $37.6 \%$ of our patients, an average annual incidence of $5.7 \%$. Only $9 \%$, however, had severe symptoms and only $55.3 \%$ of their exercise tests were abnormal. Thus 205 $(82 \%)$ patients were symptom free or had mild symptoms controlled with medication 6.6 years after operation. The policy of total revascularisation could account for these results as well as the frequency of subsequent infarction (3.6\%) which is lower than that in other series $(\geqslant 13 \%){ }^{13}$

The proportion of patients working at a mean of 6.6 years after surgery is similar to that found in other studies, ${ }^{14}$ but the proportion of smokers was less, the result perhaps of improved patient education.

We cannot compare graft patency in this study with other long term follow up data because our patients underwent angiography only for symptoms. This means that our figure for early graft failure is likely to be an overestimate. But it is clear from the angiographic data obtained in those patients undergoing a second operation that the cause of recurrent symptoms was failure of the grafts rather than development of disease in new vessels. This confirms the value of total revascularisation at the time of first operation, as well as reaffirming the need for a better understanding of graft failure and its prevention.

There is evidence that the vein wall is damaged during grafting. ${ }^{15}$ Platelets adhere to damaged vessel walls. ${ }^{16-19}$ Platelets, activated as a result of deposition, release platelet derived growth factor ${ }^{20}$ which causes the migration and proliferation of smooth muscle cells. Beyond one year $2.5 \%$ of grafts are lost each year. The cause of this loss is likely to be hyperplasfa of the intimal smooth muscle cells. ${ }^{21}$ The patho ${ }^{2}$ physiological process described has led to attempts to prolong graft patency with the currently availab!e antiplatelet drugs, aspirin and dipyridamole. Tw studies have shown that aspirin improves early graft patency. ${ }^{22}{ }^{23}$ There is no clear evidence, however, that aspirin and dipyridamole improve long term gratt patency. The reported long term benefit from aspiri and dipyridamole ${ }^{24}$ became non-significant when -3 Yates' continuity correction factor was applied Cheseboro et al's results. ${ }^{24}$

Although aspirin limited the formation of throng bus in experimental vein grafts, ${ }^{25}$ it did not prever platelet adhesion or degranulation in response to strong stimuli such as collagen. ${ }^{26-29}$ These results may explain the lack of benefit of aspirin since intimal hyperplasia, the probable cause of long term graft failure, ${ }^{21}$ is the consequence of platelet adhesion Alternatively, the failure of aspirin treatment may indicate that the role of platelets in late neointiment hyperplasia has been over-emphasised or that this process precedes the start of treatment.

The group of patients followed up in this study underwent repeat angiography at one year, and the use of aspirin and dipyridamole in addition warfarin did not confer additional benefit over wao farin alone. ${ }^{4}$ Both of these regimens have a beneficiol effect on thrombus formation. One criticism of the original study by Brookes et al was that aspirin argat dipyridamole were not started until after operation. The difference between this study, with its lack of benefit, and Cheseboro et al's study ${ }^{24}$ was the high patency rate in Brooks et al's placebo group, suggesf ing a benefit from warfarin. This would fit with the concept that early graft occlusion is the consequenge of thrombus formation. The results for longer term clinical outcome presented now confirm that the addition of high dose aspirin and dipyridamole, taken for a mean of 25 months, does not confer longer term benefit. Additionally, it has been shown that there were significantly more gastrointestinal and bleedi complications in the group taking aspirin.

The debate about aspirin dose continues. At the time the dose given to the patients in this study whess thought to be appropriate. The beneficial effects of such a high dose on early graft occlusion, however, can be achieved with lower doses. ${ }^{30}$ But we do mot know if these high dose regimens also have ${ }_{\mathbb{\Phi}}^{\top}$ detrimental effect on prostacyclin production and the blood vessel wall interaction and hence no long term benefit on graft outcome.

Conclusions

We found a favourable clinical outcome in patients 
entered into a British study in the late 1970s when surgery was performed according to current techniques. Symptoms after vein grafting were primarily caused by graft failure rather than new disease, confirming the need for total revascularisation. Additionally, the aspirin and dipyridamole results confirm those of Brooks $e t$ al in a one year follow up of these patients, ${ }^{4}$ indicating that, provided early thrombotic occlusion is prevented, these antiplatelet drugs confer no long term clinical benefit.

Current evidence suggests that coronary vein grafting is a good but palliative treatment for ischaemic heart disease. But because the patients in this study were entered at a time when total revascularisation was being undertaken routinely, it is important to continue to monitor them to see whether clinical outcome remains good. The problem of maintaining long term graft patency remains unresolved. A clearer understanding of the pathophysiology of graft failure and better antiplatelet drugs are needed.

We thank Dr N Brooks for allowing us access to the original data on these patients and $\operatorname{Dr} M$ Honey for allowing us to include his patients in the study.

\section{References}

1 Veterans Administration Coronary Artery Bypass Surgery Co-operative Study Group. Eleven-year survival in the Veterans Administration randomized trial of coronary bypass surgery for sterile angina. $N$ Engl J Med 1984;311:1333-9.

2 European Coronary Study Group. Long term results of prospective randomised study of coronary artery bypass surgery in stable angina pectoris. Lancet 1982;ii:1173-80.

3 CASS Principal Investigators and their Associates. Coronary Artery Surgery Study (CASS): a randomised trial of coronary bypass surgery. Circulation 1981;63:1-81.

4 Brooks N, Wright J, Sturridge M, et al. Randomised placebo controlled trial of aspirin and dipyridamole in the prevention of coronary vein graft occlusion. $\mathrm{Br}$ Heart $J$ 1985;53:201-7.

5 Jones TI, Dale WA. Study of peripheral autogenous vein grafts. Arch Surg 1958;76:294-309.

6 Unni KK, Kottke BA, Titus JL, Frye RL, Wallace RB, Brown AL. Pathologic changes in aortocoronary saphenous vein grafts. Am J Cardiol 1974;34:526-32.

7 Grondin CM, Lesperance J, Bourassa MG, Pasternac A, Campeau L, Grondin P. Serial angiographic evaluation in 60 consecutive patients with aortocoronary artery vein grafts 2 weeks, 1 year and 3 years after operation. $J$ Thorac Cardiovasc Surg 1974;67:1-5.

8 Bourassa MG, Fisher LD, Compeau L, Gillespie MJ, McConney M, Lesperance J. Long-term fate of bypass grafts: The Coronary Artery Surgery Study (CASS) and Montreal Heart Institute experiences.
Circulation 1986;72(suppl V):71-8.

9 Fitzgibbon GM, Leach AJ, Kean WJ, Burton JR, Kafka HP. Coronary bypass graft fate: angiographic study of 1,179 vein grafts early, one year and five years after operation. J Thorac Cardiovasc Surg 1986;91:773-8.

10 The Veterans Administration Coronary Artery Bypass Surgery Co-operative Study Group. Eleven year survival in the Veterans Administration randomised trial of coronary surgery for stable angina. $N$ Engl J Med 1984;311:1333-9.

11 Bourassa MG, Goulet C, Lesperance J. Progression of coronary arterial disease after aortocoronary bypass grafts. Circulation 1973;47-48(suppl III):127-31.

12 Seides SF, Borer JS, Kent KM, Rosing DR, McIntosh AL, Epstein SE. Long term anatomic fate of coronary artery bypass grafts and functional status of patients five years after operation. $N$ Engl $J$ Med 1978;298:1213-7.

13 Assad-Morell J, Frye RL, Connolly DC, et al. Aortocoronary artery saphenous vein bypass surgery. Clinical and angiographic results. Mayo Clin Proc 1975;50:379-86.

14 CASS Principal Investigators and their Associates. Coronary Artery Study (CASS). A randomised trial of coronary artery bypass surgery. Quality of life in patients randomly assigned to treatment groups. Circulation 1983;68:951-9.

15 Brody WR, Angell WW, Kosck JC. Histologic fate of the venous coronary artery bypass in dogs. Am J Pathol 1972;66:111-30.

16 Lewis JC, Kottke BA. Endothelial damage and thrombocyte adhesion in pigeon atherosclerosis. Science 1977;196:1007-9.

17 Harker L, Ross R, Slichter SJ, Scott CR. Homocystineinduced arteriosclerosis. The role of endothelial cell injury and platelet response in its genesis. $J$ Clin Invest 1976;58:731-41.

18 Shaub RA, Rawling A, Keith JC. Platelet adhesion and myointimal proliferation in canine pulmonary arteries. Am J Pathol 1981;104:13-22.

19 Jorgensen L, Packham MA, Rowsell H, Mustard J. Deposition of formed elements of blood on the intima and signs of intimal injury in the aorta of rabbit, pig and man. Lab Invest 1972;27:341-50.

20 Antioniades HN, Scher CD, Stiles CD. Purification of human platelet-derived growth factor. Proc Natl Acad Sci USA 1979;76:1809-13.

21 Lawrie GM, Lie JT, Morris GC, Beazley HL. Vein graft patency and intimal proliferation after aortocoronary bypass: early and long term angiopathologic correlations. Am J Cardiol 1976;38:856-62.

22 Brown BG, Cukingnan RA, Derouen T, et al. Improved graft patency in patients treated with platelet inhibiting therapy after coronary bypass surgery. Circulation 1985;72:138-46.

23 Cheseboro JH, Clements IP, Fuster V, et al. A plateletinhibitor-drug trial in coronary artery bypass operations. Benefit of perioperative dipyridamole and aspirin therapy on early postoperative vein graft patency. $N$ Engl J Med 1982;307:73-8.

24 Cheseboro JH, Fuster V, Elveback LR, et al. Effect of dipyridamole and aspirin on late vein graft patency after coronary bypass operations. $N$ Engl $J$ Med 
1984;310:209-14.

25 Josa M, Lie JT, Bianco RL, Kaye MP. Reduction of thrombosis in canine coronary bypass vein grafts with dipyridamole and aspirin. Am J Cardiol 1981; 47:1248-54.

26 Kinlough-Rathbone RL, Groves HM, Cazenave JP, Richardson M, Mustard J. Effect of dipyridamole and aspirin on platelet adherence to damaged rabbit aortae in vitro and in vivo [Abstract]. Fed Proc 1978;37:260.

27 Tschopp TB. Aspirin inhibits platelet aggregation on but not adhesion to, collagen fibrils: an assessment of platelet adhesion and deposited platelet mass by morphometry and $51 \mathrm{Cr}$-labelling. Thromb Res 1957; 11:619-32.

28 Gershlick AH, Syndercombe-Court D, Murday AJc. Lewis CT, Mills PG. Adverse effect on high dose aspirin on platelet adhesion to experimental auto $\frac{}{9}$ genous vein grafts. Cardiovasc Res 1985;19:770-6.

29 Kinlough-Rathbone RL, Cazenave JP, Packham MA Mustard J. Effect of inhibitors of the arachidonatê pathway on the release of granule contents frong rabbit platelets adherent to collagen. Lab Inves 1980;42:28-34.

30 Lorenx RL, Schacky CV, Weber M, et al. Improved aortocoronary bypass patency by low dose aspirin (100 mg daily). Lancet 1984;i:1261-4. 